MASONRY REPAIR LIME-BASED MORTARS: FACTORS AFFECTING THE

MECHANICAL BEHAVIOR

J. Lanas and J.I. Alvarez*

Departamento de Química, Universidad de Navarra, 31080 Pamplona, Spain

$\mathbf{N}^{\mathbf{0}}$ of pages: 34

$\mathbf{N}^{\mathbf{0}}$ of tables: 7

$\mathbf{N}^{\mathbf{0}}$ of figures: 7

Keywords: A: Curing. C: Carbonation. C: Compressive Strength. C: Mechanical Properties. D: $\mathrm{Ca}(\mathrm{OH}) 2$

Please, send all correspondence to:

Dr. José I. Alvarez-Galindo

Dpto. de Química y Edafología

Fac. de Ciencias

Universidad de Navarra

$\mathrm{C} /$ Irunlarrea $\mathrm{s} / \mathrm{n}$

31.080 Pamplona (Navarra)

Spain

Phone: 34948425600

Fax: 34948425649

E-mail: jalvarez@unav.es 


\title{
MASONRY REPAIR LIME-BASED MORTARS: FACTORS AFFECTING THE MECHANICAL BEHAVIOR
}

\author{
J. Lanas and J.I. Alvarez* \\ Departamento de Química, Universidad de Navarra, 31080 Pamplona, Spain
}

ABSTRACT: The increasing use of lime-based mortars for the restoration of historic buildings and structures justifies the research on these materials. The focus of this paper is the effect of technological variables on pore structure and mechanical properties of lime-based mortars. The influence of curing time, binder:aggregate ratio, aggregate attributes and porosity is discussed. Mortars prepared with aerial lime, varying aggregate types and binder:aggregate ratios ranging from (1:1) to (1:5) by volume were tested. Compressive and flexural strength measurements, as well as X-ray diffraction and thermal studies, were performed after 3, 7, 28, 91, 182 and 365 days. A strong increase in strength of mortar mixtures after 365 curing days (as compared to 28 curing days) is found. In spite of the fact that larger amounts of binder increase the total porosity, the strength of these mixtures is also increased. A good interlocked structure is obtained as binder contents increase. Also, higher porosities allow better portlandite carbonation. A relationship between mechanical properties and pore structure was established. However, in case of binder excess, the increase in voids leads to a strength reduction. The use of calcareous aggregates improves strength more as compared to the use of siliceous aggregates. Factors as grain size distribution and grain shape of the aggregates have also been considered.

Keywords: A: Curing. C: Carbonation. C: Compressive Strength. C: Mechanical Properties. D: $\mathrm{Ca}(\mathrm{OH})_{2}$ 


\section{Introduction}

An adequate choice of repair mortars is critical to the success of a restoration process. Compatibility between the new repair mortar and the original components of the masonry is very desirable $[1,2]$. This compatibility must be reflected in several aspects: (i) chemical compatibility between the repointing mortar and the old materials (stone or brick and its bedding mortar); (ii) physical compatibility, with special reference to processes of solubility and of water transport; (iii) structural and mechanical compatibility: the strength of repair mortar has to be similar to the ancient ones.

During the $20^{\text {th }}$ century, in the restoration of masonry structures, there has been a tendency to replace mortars with cement-based mortars. However, in several recent cases, extensive damage to the ancient masonry due to incompatibility of the cementbased mortars with the old materials has been clearly established [2-4].

Indeed, cement-based mortars show a high content of soluble salts, potentially dangerous for decay of ancient mortar by crystallization and/or hydration (cycles) [4]. Also, cement-based mortars are less permeable than lime mortars, retaining an excess water, which initiate alteration phenomena. Finally, cement-based mortars exhibit a high compressive strength, but far from being favorable, this is a source of problems. Masonry structures show some degree of movement resulting from creep or thermal effects. A repair mortar should be capable of accommodating movement. A too strong repair mortar restrains movement and leads to stress that can cause failure in the original masonry $[1,5]$.

Several factors have contributed to the disuse of lime-based mortars: (i) the massive use of Portland cement in building technology; (ii) the low strengths attributed to the lime mortars; (iii) lime mortars take a long time to harden; (iv) the absence of rigorous studies about the characteristics and properties of lime-based mortars. 
As a consequence, traditional know-how in the manufacture and application of lime mortars has mostly been lost. The scarce literature about these mortars does not explain diverse questions. For example, the variation of compressive strength in the course of time: Degryse et al. [2] state that modern copies of Roman lime mortars obtain most of their strength through carbonation after 28 days (as a function of the type of aggregate), but this idea conflicts with the knowledge of a very slow setting in these mortars [6]. Other questions refer to the most suitable binder:aggregate ratio: Cazalla et al. [7] suggest a new repair lime mortar with binder:aggregate ratios $\leq 1: 4$, because the mortar is more rigid and with fewer cracks than 1:3, but Moropoulou et al. [3] suggest that 1:3 could be selected as the proper ratio for restoration syntheses. In any case, in the previously cited works, the small amount of samples studied hinders the establishing of significant conclusions.

However, an increasing interest in the use of lime-based mortars for the restoration of historic structures has been observed. International centers, such as ICOMOS or ICCROM, have recommended the use of materials similar in composition and properties to the original ones for the restoration works $[8,9]$.

The influences on mechanical properties of the different types of aggregates have been checked. Degryse et al. [2] have established the effect of different types of aggregates in the mechanical behavior in modern copies of Roman lime mortars: about the mortar strength, the authors explain that it can be enhanced by adding limestone to the mix (taking into account the grain size distribution), also by adding crushed ceramics to a volcanic material/limestone mix, but overcoat by using only limestone and volcanic material. As a conclusion, the type of aggregate made of crushed ceramics is suitable when frost resistance has no interest. It can be used in water proofing requirements. 
Mortars prepared with limestone and volcanic aggregates show a good freeze-thaw resistance and strength.

Many reasons and advantages of lime based mortars can be noticed: (i) a chemical and physical compatibility with the ancient mortar, due to their similar composition; (ii) the mechanical behavior, very different from cement mortars: lime mortar is softer, more deformable [10] and it is able to accommodate movement in masonry structures [5]; (iii) the decrease of the cost due to the low price of lime as a binder.

In this context, the purpose of this paper is to study the mechanical behavior of different new aerial lime mortars in long-term tests in order to establish significant conclusions about the properties of these mortars so that these can be used to select a suitable mortar mixture for restoration works.

Specifically, the aim of the present work is to clarify how different factors affect the mechanical strengths of lime mortar. It explains the influence of curing time, binder:aggregate ratio, type of aggregate (nature, grain size distribution and shape) and porosity.

\section{Experimental work}

\subsection{Mortar preparation}

Two different aerial limes have been used to prepare the mortars: Ecobat ${ }^{\circledR}$ (lime A) and Estavol $^{\circledR}$ (lime B) (supplied by CALINSA, S.A, Navarra). Both are commercial hydrated lime powders of the class CL90 according to Spanish standards [11]. Table 1 gives their chemical characterization (according to the European Standard [12]) and Table 2 presents their mineralogical analysis by X-ray diffraction (XRD). A negligible amount of calcite is observed. Both limes have a high purity. 
CTH Navarra (Navarra, Spain) has supplied the aggregates used. These are commercial aggregates, with controlled granullometry (Fig. 1) and a constant chemical and mineralogical composition (Table 3). Aggregates 1 and 2 (Ag-1, Ag-2) show quartz as the main component, as can be seen by XRD (Table 4). A certain amount of calcite is also present (ca. $34 \%$ in Ag-1; $18 \%$ in Ag-2). Other compounds could be present in these aggregates (as complex silicates), but in very small amount $(<10 \%)$, because they have not been detected by XRD and the chemical analysis shows low $\mathrm{R}_{2} \mathrm{O}_{3}(\mathrm{Fe}, \mathrm{Al}$ and Ti oxides) percentages.

Aggregates 3 and 4 (Ag-3, Ag-4) are calcitic aggregates (>> $90 \%$ of crystalline phases are calcite). They come from pure limestone.

As for the silica aggregates, Ag-1 is made up of pebbles, with rounded shapes; Ag-2 is made up of crushed stones, with angular edges. As for the limestone aggregates, Ag-3 and Ag-4 present different grain size distributions.

The binder:aggregate ratios selected for this study vary around 1:3 by volume, as this is the most cited ratio in literature [3,13-17]. The binder:aggregate ratios $(\mathrm{B} / \mathrm{Ag})$ prepared are $(1: 1),(1: 2),(1: 3),(1: 4)$ and (1:5), by volume. Volume proportions of components were converted in weight proportions to avoid imprecision on the mixing process. Table 5 shows the equivalences.

Mortar mixtures were prepared using the correct amount of water required to obtain normal consistency and a good workability (measured by the flow table test) [18]. A water/binder ratio ranging from 0.5 (1:1 specimens) to $1.2(1: 5$ specimens $)$ gave a suitable workability. The mixer used was a Proeti ETI 26.0072. Aggregate and lime were blended for $5 \mathrm{~min}$. Water was then added and mixed for $5 \mathrm{~min}$ at low speed, and finally for $1 \mathrm{~min}$ at high speed. The mortars were molded in prismatic 40x40x160 mm casts and demolded $72 \mathrm{~h}$ later. The pastes were slightly pressed to remove any air 
bubbles and voids. Curing was executed in ambient laboratory conditions ( $\mathrm{RH} 60 \pm 10 \%$ and $20 \pm 5^{\circ} \mathrm{C}$ ) until the test day.

A total of 9 specimens of each $\mathrm{B} / \mathrm{Ag}$ ratio were prepared, hence 180 specimens of each lime (45 of each aggregate) have been studied. Test and analyses were conducted using the techniques described below after curing times of 3, 7, 28, 91 and 365 days: one specimen at 3 days after curing was tested, 2 after 7 days, 3 after 28, 2 after 91 days, 1 after 365 days. The coefficients of variation were below $10 \%$. Taking about the results of the analyses of lime A mortars, a small change in the experimental design was made: specimens of lime B were also tested at 182 days after curing in order to obtain one more datum at medium-term. Thus 1 specimen was studied at 3, 7 and 365 days, while 2 specimens were studied at 28, 91 and 182 days, with the aim to increase the significance of the intermediate curing period. In compressive strength results, the coefficients of variation were below $15 \%$.

\subsection{Analytical methodology}

\subsubsection{Mechanical properties}

The three-point flexural tests were carried out using a Frank/Controls 81565 compression machine at low rates of loading $(4 \mathrm{~mm} / \mathrm{min})$. Flexural strength determination was done on a Ibertest IB 32-112V01.

Compression strength tests were conducted on the two fragments of each specimen resulting from the preceding flexural test. Compression strength determination was done on a Proeti ETI 26.0052, the rate of loading was $10 \mathrm{~mm} / \mathrm{min}$. The reported results are the average value of the identical specimens. 


\subsubsection{Mineralogical analysis}

A significant portion of each specimen was ground in an agate mortar. Samples were taken from the core and from the edges of the mortar specimens to avoid differences in the carbonation depth. Mineralogical phases were determined by means of XRD using a Bruker D8 Advance diffractometer (Karlsruhe, Germany), according to the diffraction powder method, with $\mathrm{CuK}_{\alpha 1}$ radiation, $0.02^{\circ} 2 \theta$ increment and $1 \mathrm{~s} \cdot \mathrm{step}^{-1}$, sweep from 2 to $90^{\circ} 2 \theta$. The results were compared with the ICDD database.

\subsubsection{Thermal analysis}

Differential thermal and thermogravimetric analysis (DTA-TG) were carried out using a simultaneous TGA-sDTA 851 Mettler Toledo thermoanalyser (Schwerzenbach, Switzerland) using alumina crucibles, with holed lids, at $20^{\circ} \mathrm{C} \min ^{-1}$ heating rate, under static air atmosphere, from ambient temperature to $1200^{\circ} \mathrm{C}$.

\subsubsection{Pore structure}

The pore structure was evaluated in two ways in specimens after 365 days of curing, in order to assure a high level of carbonation. 2 methods were used:

a) Open porosity measurement: the total porosity is expressed as $\mathrm{P}$, in percent, and is determined according to the water saturation test [19] with a hydrostatics balance.

b) Pore size distribution is evaluated using the mercury intrusion porosimetry technique with a Micrometrics 9320 Poresizer mercury porosimeter which automatically registers pressure, pore diameter, intrusion volume and pore surface area. 


\section{Results and discussion}

\subsection{Influence of curing time}

Lime-based mortars harden in two ways: at early ages, the excess water is lost and shrinkage occurs. Almost at the same time, the carbonation process of portlandite transforming into calcite starts.

It is well known that lime mortars can take many years to reach total carbonation [20]. Through XRD and TG, the degree of mortar carbonation can be determined. After 1 year of curing, a certain amount of portlandite remained uncarbonated in all the samples, as can be seen through the occurrence of portlandite diffraction peaks in XRD patterns and the weight loss at $\sim 450^{\circ} \mathrm{C}$ in $\mathrm{TG}$ results, which indicates $\mathrm{Ca}(\mathrm{OH})_{2}$ dehydroxilation (Table 6 shows the example of lime B with Ag-4 aggregates) [21].

Obviously, because of binder hardening, the mechanical strengths increase with curing time. However, the age at which lime mortars exhibit their peak strength is unknown. It is also unknown how the mortar strength varies quantitatively with curing time, i.e. the degree of carbonation. Some authors state that modern copies of Roman lime mortars reach most of their strength through carbonation after 28 curing days due to the type of aggregate [2].

The results of compressive and flexural strength testing have shown a vast increment in strength between 28 days and 365 days of curing: this is a general behavior, independent of aggregate type and dosage. Fig. 2 shows the compressive and flexural strengths of the lime A specimens in different ratios, prepared with different aggregates, as a function of curing time.

Regarding the results, it can be stated that the mortars with high $\mathrm{B} / \mathrm{Ag}$ ratios have undergone a greater strength increment (ratios 1:1 and 1:2). For example, lime A mortar 
with Ag-3 (1:1) B/Ag has shown a compressive strength 3.5 times more at 365 days than at 28 days, and a flexural strength twice more after 365 days than after 28 days.

This is due to the portlandite content of the mixtures: a longer curing time allows a higher rate of carbonation, and mortars with higher portlandite contents clearly improve their strength. Furthermore, it can be seen that lime-based mortars need a long time for obtain their strength. A curing period of 28 days is not enough: a compressive strength increment of twice or more can be determined after 365 days.

In this respect, lime B mortars have also been also tested after 182 curing days, in view of the previous results that indicate the importance of medium and long term curing. Fig. 3 shows compressive and flexural strengths of lime B mortars with different aggregates. It can be noticed that the $(1: 1) \mathrm{B} / \mathrm{Ag}$ mortar has developed an outstanding increment in strength between 182 and 365 curing days. This behavior has been noted in all (1:1) mortars evaluated.

A slight downward trend in the results of the (1:2) to (1:5) mortars has been determined between 182 and 365 days. For these mortars, the maximum strength value was reached at 182 curing days. Since at 182 curing days (and also at 365 days) portlandite remains in the mortars, a hypothesis could give an explanation for this fact: mortars exhibit the highest strength value when a certain amount of portlandite stays uncarbonated. The decrease of this small amount produces a slight drop in mortar strength. The preservation of a certain ratio $\mathrm{CaCO}_{3} / \mathrm{Ca}(\mathrm{OH})_{2}$ contributes in an unknown way to the highest strength. Fig. 3 has shown this fact: for example, in compressive strength of specimens prepared with Ag-4, the suitable $\mathrm{CaCO}_{3} / \mathrm{Ca}(\mathrm{OH})_{2}$ was reached before by mortars with less amount of binder, so the greatest strength was obtained in a shorter time. Mortar with (1:5) B/Ag has attained the highest strength at $\sim 90$ curing days, and after this value, a decrease in the strength can be checked. (1:4), (1:3) and (1:2) B/Ag 
mortars have begun their drops respectively later, and they are less marked. For (1:1) mortar the adequate $\mathrm{CaCO}_{3} / \mathrm{Ca}(\mathrm{OH})_{2}$ still was not reached after 365 days of curing. In this sense, Moropoulou et al. [22] indicate that the occurrence of crystalline portlandite in lime mortars involves a porosity decrease and a strength increment.

On the other hand, the strengths determined at early ages (between 3 and 28 curing days) are not conclusive, because they are strongly influenced by the water content of the mixture. Most of the mortars are still losing water at 28 curing days (e.g. Fig. 4 shows, as an example, the weight loss of the lime B mortars with Ag-4 in relation to curing time). Also, at early ages (28 curing days) the degree of carbonation was negligible as the amount of $\mathrm{Ca}(\mathrm{OH})_{2}$, which changes slightly, shows in the TG results (Table 6).

\subsection{Influence of binder:aggregate ratio}

The (1:1) B/Ag specimens tested after 1 curing year systematically show the highest strength (Figs. 2 and 3). In general, binder decrease in the mortars has reduced its strength. Differences in strength between ratios (1:3), (1:4) and (1:5) are smaller compared to the (1:1) and (1:2) B/Ag mixtures. Values higher than expected were obtained in compressive strength for (1:1) mortars. These results disagree with references that state: (i) the (1:3) radio is the most suitable mixture for repair mortars, due to its highest strength [3]; (ii) the occurrence of some cracks due to the shrinkage when the binder amount increase above of (1:3) ratio [7]; (iii) the low strengths mainly achieved by lime mortars $[13,15]$; (iv) the increment of strength when aggregate content increases [23].

The results of the present work indicate that $(1: 1) \mathrm{B} / \mathrm{Ag}$ provides the highest mechanical strength. Values after 1 year for $(1: 1)$ mortars were confined to the $2.30-5.36 \mathrm{~N} / \mathrm{mm}^{2}$ 
range of compressive strength, with an average value of $3.92 \mathrm{~N} / \mathrm{mm}^{2}$. No cracks owing to shrinkage were observed in the surface of these specimens.

Cement-based mortars also increase in strength when binder proportions are raised [1]. However, while this strength rise could be related to lower porosities, in lime-based mortars a binder increment leads to a porosity increase, as considered later (Fig. 5).

Given the aforementioned facts, it can be established that lime-based mortars develop the highest strengths with large binder amounts. Nevertheless, this statement has a limit: Fig. 5 shows compressive strengths after 1 year in lime A mortars with ratios (1:1) to (1:5) and also (2:1), (4:1) and pure lime mortar, without aggregate. A strength increase could be observed in $(2: 1)$ mortar, but a strong strength reduction has been prove when the binder amount increases beyond this ratio. The lower amount in aggregate has produced internal and surface cracks because of binder increment. Moreover, a certain portion of the lime fraction abandons its binder function and acts as a filler [23]. Therefore, a certain amount of aggregate must be contained into the mortar to assure an adequate joint mechanical work by binder and aggregate.

\subsection{Influence of the aggregate characteristics.}

From the strength results of specimens tested after 1 year (Figs. 2 and 3), it was observed that the grain size distribution of the aggregates is the most important attribute in relation to aggregate characteristics. An adequate grain size distribution (Fig. 1) has allowed the development of a high strength in the mortar. For example, in Figs. 2 and 3, the results show the highest flexural strength in mortars made with Ag-4. Also Ag-4 show very high compressive strength results, similar to the Ag-3 ones. These two aggregates, Ag-3 and Ag-4 have presented a grain size distribution without rock 
fragments (gravel $>2 \mathrm{~mm}$ ) [25]. However, Ag-1 and Ag-2, which contain pebbles, produce a lower mortar strength than Ag-3 and Ag-4, as can be seen after 1 year.

This influence of grain size distribution of the aggregates shows an agreement with previous works $[2,6]$.

In some previous papers, the type of aggregate has been established as a factor affecting strength $[2,6]$. A source of reactive silica (for example in volcanic or crushed ceramics aggregates) could react with the lime, producing $\mathrm{CSH}$ compounds in the interface that improve mortar strength. The addition of crushed ceramic aggregates is suitable in waterproofing requirement [2]. The effect of crushed brick or pozzolanic physicochemically active aggregates in order to improve the mortar's performance have also been extensively studied [6].

In the present work, chemical and mineralogical composition of the aggregates used have been determined (Tables 3 and 4). These compositions are almost invariable due to the commercial origin of the aggregates.

Ag-1 and Ag-2 are silica aggregates (quartz in their composition with small amounts of calcite). The content of pozzolanic materials does not exceed $10 \%$ in these aggregates. Therefore, the reaction between the lime and the silica aggregates used in this work is unlikely or, at least, insignificant. This fact can be seen in the strength reduction when a silica aggregate was used instead of a limestone aggregate (Figs. 2 and 3). Ag-3 and Ag4 are pure limestone aggregates. It can be clearly established that these limestone aggregates have produced the higher mortar strengths. The use of silica aggregates has produced a lower mortar strength. The similarity between a calcitic binder matrix and a limestone aggregate structure could be related to this increase of strength. In this sense: (i) the absence of discontinuity between aggregate and binder matrix improves strength, because interfacial zones with special microstructures are not present. The mechanical 
behavior of mortars has been related to these special microstructure zones [26]; (ii) the syntaxial growth process could take place during portlandite carbonation due to the calcite of the aggregate that provides nucleating sites for the crystal growth. This process develops strength enhancing the binder-aggregate interface [20,27].

Also, the shape of the aggregate grains appears to have some influence. As a matter of fact, specimens with Ag-2 have shown higher strengths than specimens with Ag-1. Given that grain size distributions and nature are very similar, the lower strength when Ag-1 was used should be due to another reason. Made with rounded grains, Ag-1 has hindered a suitable adherence and the obtaining of a packed structure [20]. Ag-2 has improved mechanical strength because of the good packing of its angular shapes, which were produced during the crushing stone process.

\subsection{Porosity influence}

It has clearly been determined that porosity influences the strength of cement-based mortars $[1,28]$. As previously indicated, porosity reduction causes a strength increase. However, in lime-based mortars larger amounts of binder cause porosity increase, because lime is a very porous material. Table 7 shows the open porosity of the tested specimens. The highest values are seen in $(1: 1) \mathrm{B} / \mathrm{Ag}$, and porosity reduction was obtained when aggregate contents increase. Contrary to cement-based mortars, the specimens with highest strength are the mortars with the highest porosity.

This could be explained as follows:

a) A larger binder content allows improvement of strength because of a good interlocked, continuous structure. An aggregate increase causes discontinuities in the structure owing to the increase in interfaces. The limit for this strength increment, due to the binder amount, has been previously 
discussed in 3.2. Beyond this limit, the initial strength because of the low amount of the aggregate. As a consequence, the total strength drops sharply.

b) The parallel porosity increase due to the large amounts of binder has two opposite influences in the mechanical behavior:

(i) an increase in voids should lead to a strength reduction. In Fig. 5 this event could prevail when binder amount increases beyond of $(2: 1)$ $\mathrm{B} / \mathrm{Ag}$.

(ii) an increase in degree of carbonation should provide an increase in strength. A porosity increment in lime mortars allows a faster and more complete carbonation [29,30]: the transformation of portlandite into calcite leads to a strength increase, as discussed in 3.1. In Fig. 5, the predominance of this event could explain the $(2: 1) \mathrm{B} / \mathrm{Ag}$ values.

Both factors will converge in time, because the carbonation, increasing the volume owing to the transformation of portlandite into calcite, achieves a porosity decrease (i.e. a void reduction) as new calcite formed a gradually fills of pores. The porosity reduction hinders the $\mathrm{CO}_{2}$ flow, so the carbonation is a self-limiting process [30].

Figures 6 and 7 show the pore size distribution in specimens with different B/Ag ratios. The results have confirmed that a total porosity increase is observed when the lime content increases. Lime mortars, in general, have shown mainly medium and large pore radii $(0.3-100 \mu \mathrm{m})$. In specimens with siliceous aggregates (Fig. 6), a reduction of large pores $(100-10 \mu \mathrm{m})$ and an increase of small pores $(0.1-0.01 \mu \mathrm{m})$ can be observed when aggregate amounts increase. Specimens with limestone aggregate (Fig. 7) have shown 
no small pores $(0.1-0.01 \mu \mathrm{m})$, therefore small radius pores have been attributed to siliceous aggregates [20].

This could be another reason to explain the different mechanical behavior of different types of aggregate nature: siliceous aggregates provide small radius pores, which obstruct an adequate $\mathrm{CO}_{2}$ flow through the mortar. As a consequence, the mortar carbonation decreases and the strength decreases. Nevertheless, limestone aggregates, increasing the amount of medium and large radius pores, allow mortar carbonation and improve mortar strength.

Moreover, during the drying and the crystallization process, stress is higher in smaller pores due to their low radius [31]. This stress could produce cracks during shrinkage and subsequent calcite crystallization. The cracks can move into the larger pores, and as a consequence the strength decreases. Therefore, materials (lime or aggregate) providing the smaller pores can develop a strength reduction.

\section{Conclusions}

(1) As for the curing time, a vast increment of the compressive and flexural strengths between 28 and 365 curing days was determined (compressive strength increases twice or more from 28 to 365 days).

(2) The period to exhibit a maximum strength has been determined as a function of the binder content: lower $\mathrm{B} / \mathrm{Ag}$ ratio mortars have shown a slight decrease in the strength when the curing time increased. The maximum strength has been related to the presence of a certain amount of uncarbonated portlandite.

(3) A correlation between binder amount and mortar strength was observed: a binder content increase improves strength within a limit. Binder amounts beyond (2:1) B/Ag ratio have shown a strong strength reduction. It is stated that a large binder content 
produces an interlocked structure, while the aggregates cause discontinuities in the structure. The porosity increase due to the binder makes carbonation easier, so mortar strength improves. However, in case of binder excess, the increase in voids leads to a strength reduction.

(4) A suitable grain size distribution of the aggregate has allowed higher mortar strengths.

(5) The type and shape of the aggregate influence the mortar strength. Angular limestone has been shown to improve strength. The lack of discontinuity between the binder matrix and the aggregate of the same nature improves the strength, as well as a good packing of the aggregate with angular edges. Limestone aggregates have shown medium and large radius pores that allow carbonation, avoiding stress during drying and the crystallization process.

\section{Acknowledgements}

The present study was supported by the Spanish Ministerio de Ciencia y Tecnología, Plan Nacional de Investigación, Desarrollo e Innovación Tecnológica (I+D+I) program, Project MAT2000-1347.

The authors would like to thank Dr. M.A. Bello and Dr. J.L. Pérez Bernal from the Analytical Chemistry Department at University of Sevilla for their help with intrusion porosimetry technique determinations. We are also grateful to Fernando Moreno (CALINSA) and José María Galech (CTH, Navarra) for the material supplied. 


\section{References}

[1] M.J. Mosquera, D. Benitez, S.H. Perry, Pore structure in mortars applied on restoration. Effect on properties relevant to decay of granite buildings, Cem. Concr. Res. 32 (2002) 1883-1888.

[2] P. Degryse, J. Elsen, M. Waelkens, Study of ancient mortars from Salassos (Turkey) in view of their conservation, Cem. Concr. Res. 32 (2002) 1457-1563.

[3] A. Moropoulou, A.S. Cakmak, G. Biscontin, A. Bakolas, E. Zendri, Advanced Byzantine cement based composites resisting earthquake stresses: the crushed brick/lime mortars of Justinian's Hagia Sophia, Constr. Build. Mater. 16 (2002) $543-552$.

[4] C. Rodriguez-Navarro, E. Hansen, W.S. Ginell, Calcium hydroxide crystal evolution upon aging of lime putty, J. Am. Ceram. Soc. 81 (11) (1998) 3032-3034.

[5] A.W. Hendry, Masonry walls: materials and construction, Constr. Build Mater. 15 (2001) 323-330.

[6] G. Baronio, L. Binda, N. Lombardi, The role of brick pebbles and dust in conglomerantes based on hidrated lime and crushed bricks, Constr. Build. Mater. 11 (1997), 33-40.

[7] O. Cazalla, C. Rodriguez-Navarro, E. Sebastian, G. Cultrone, Aging of lime putty: effects on traditional lime mortar carbonation, J. Am. Ceram. Soc. 83 (5) (2000) 1070-1076.

[8] Venice Charter, International Charter for the conservation and restoration of monuments and sites, Venice, 1964 (web site: <http://www.icomos.org/docs/venice -charter.html>). 
[9] Conclusions of the Symposium "Mortars, cements and grouts used in the conservation of historic buildings", Rome, Mater. Struct., 23 (1990) p. 235.

[10] B.T. Rosson, K. Sфyland, T. E. Boothby, Inelastic behavior of sand-lime mortar joint masonry arches, Eng. Struct. 20 (1-2) (1998) 14-24.

[11] UNE-EN 459-1, Building Lime. Part 1: Definition, specification and conformity criteria (1996).

[12] UNE-EN 196-2, Methods of testing cement. Part 2: Chemical Analysis of cement (1996).

[13] R. Malinowski, Ancient mortars and concretes, durability aspects, Mortars, Cements and Grouts used in Conservation of Historic Buildings, Proceedings of the Symposium, ICCROM, Rome (1981) pp. 341-350.

[14] M. Frizot, PhD thesis (in French), Université de Dijón, Centre de Recherches sur les techniques greco-romains, 1975, pp. 57-137.

[15] L. Sbordoni-Mora, Les matériaux des enduits traditionnels, Mortars, Cements and Grouts used in Conservation of Historic Buildings, Proceedings of the Symposium, ICCROM, Rome (1981) pp. 375-383.

[16] A. Moropoulou, A.S. Cakmak, N. Lohvyn, Earthquake resistat construction techniques and materials on Byzantine monuments in Kiev, Soil. Dyn. Earthq. Eng. $19(2000) 603-615$.

[17] A. Martín, Ensayos y experiencias de alteración en la conservación de obras de piedra de interés histórico artístico, Ed. Ramón Areces, Madrid, 1990.

[18] UNE 83-811-92, Mortars. Test Methods. Fresh Mortars. Determination of consistence. Flow Table (reference Method) (1992).

[19] RILEM, 1980. Recommended tests to measure the deterioration of stone and asses the effectiveness of treatment methods, Mater. Struct. 13 (1980) 175-253 
[20] O. Cazalla, Morteros de cal. Aplicación en el patrimonio histórico, Unpublished $\mathrm{PhD}$ thesis (in Spanish), Universidad de Granada, Granada, 2002.

[21] T. Hatakeyama, Z. Liu, Handbook of Thermal Analysis, Wiley, UK, 1988.

[22] A. Moropoulou, G. Biscontin, A. Bakolas, K. Bisbikou, Technology and behavior of rubble masonry mortars, Constr. Build. Mater. 11 (2) (1997) 119-129.

[23] Guía práctica de la cal y el estuco, Editorial de los Oficios, Leon, 1998.

[24] D. Pellicer, El hormigón armado en la construcción arquitectónica, Editorial Bellisco, Madrid, 1989.

[25] USDA. United State Departament of Agriculture. Natural Rersources Conservation Service. Soil Survey Laboratory Methods Manual, Natl. Soil Surv. Cent. SSIR 42, p. 693 (1996).

[26] P.J.P. Gleize, A. Müller, H.R.Roman, Microstructural investigation of a silica fume-cement-lime mortar, Cement Concrete Comp. 25 (2) (2003) 171-175.

[27] M. Heikal, M.H. El-Didamony, M.S. Morsy, Limestone-filled pozzolanic cement, Cem. Concr. Res. 30 (2000) 1827-1834.

[28] S.P. Pandey, R.L. Sharma, The influence of mineral additives on the strength and porosity of OPC mortar, Cem. Concr. Res. 30 (2000) 19-23.

[29] P. Mira, V.G. Papadakis, S. Tsimas, Effect of lime putty addition on structural and durability properties of concrete, Cem. Concr. Res. 32 (2002) 683-689.

[30] D.R. Moorehead, Cementation by the carbonation of Hydrated Lime, Cem. Concr. Res. 16 (1986) 700-708.

[31] G.W. Scherer, Crystallization in pores, Cem. Concr. Res. 29 (1999) 1347-1358. 
Table 1. Chemical analysis of the main components of the aerial limes ${ }^{\mathrm{a}, \mathrm{b}}$.

\begin{tabular}{|c|c|c|c|c|c|c|c|c|}
\hline Lime & I. L. (\%) & $\mathrm{SiO}_{2}(\%)$ & $\mathrm{CaO}(\%)$ & MgO (\%) & $\mathrm{R}_{2} \mathrm{O}_{3}{ }^{\mathrm{b}}(\%)$ & $\mathrm{SO}_{3}(\%)$ & $\mathrm{Na}_{2} \mathrm{O}(\%)$ & $\mathrm{K}_{2} \mathrm{O}(\%)$ \\
\hline $\begin{array}{c}\text { Lime A } \\
\left(\text { Ecobat }^{\mathbb{B}}\right)\end{array}$ & 25.25 & 1.03 & 68.53 & 3.29 & 0.89 & 1.37 & 0.09 & 0.05 \\
\hline $\begin{array}{c}\text { Lime B } \\
\left(\text { Estavol }^{\circledR}\right)\end{array}$ & 25.46 & 0.71 & 68.26 & 3.55 & 0.55 & 0.96 & 0.07 & 0.04 \\
\hline
\end{tabular}

${ }^{a}$ Percentages related to original dry lime.

${ }^{b}$ The methods specified by the European Standard EN-196 were followed for the chemical analyses.

${ }^{c} \mathrm{R}_{2} \mathrm{O}_{3}$ expresses the percentage of $\mathrm{Fe}, \mathrm{Al}$ and $\mathrm{Ti}$ as oxides. 
Table 2. Results of X-ray diffraction in aerial limes.

\begin{tabular}{lcc}
\hline Lime & $\begin{array}{c}\text { Portlandite } \\
\left(\mathbf{C a}(\mathbf{O H})_{2}\right) \\
\text { ICDD 44-1481 }\end{array}$ & $\begin{array}{c}\text { Calcite } \\
\left(\mathbf{C a C O}_{3}\right) \\
\text { ICDD 05-0586 }\end{array}$ \\
\hline \multirow{2}{*}{ Lime A } & $* * *^{\mathrm{a}}$ & $\mathrm{S}^{\mathrm{b}}$ \\
Lime B & $* * *$ & $\mathrm{~S}$ \\
\hline${ }^{\mathrm{a}}>90 \%$ & \\
${ }^{\mathrm{b}}$ Small amount $(5-10 \%)$ &
\end{tabular}


Table 3. Chemical analysis of the main components of the aggregates ${ }^{\mathrm{a}, \mathrm{b}}$.

\begin{tabular}{|c|c|c|c|c|c|c|c|c|}
\hline Aggregate & I. L. (\%) & $\mathrm{SiO}_{2}(\%)$ & $\mathrm{CaO}(\%)$ & MgO (\%) & $\mathrm{R}_{2} \mathrm{O}_{3}{ }^{\mathrm{b}}(\%)$ & $\mathrm{SO}_{3}(\%)$ & $\mathrm{Na}_{2} \mathrm{O}(\%)$ & $\mathrm{K}_{2} \mathrm{O}(\%)$ \\
\hline Ag-1 & 15.06 & 57.69 & 19.00 & 1.53 & 5.69 & 0.08 & 0.36 & 0.48 \\
\hline Ag-2 & 9.35 & 72.29 & 9.84 & 1.50 & 6.00 & 0.10 & 0.37 & 0.50 \\
\hline Ag-3 & 43.10 & 0.49 & 52.83 & 2.28 & 1.14 & 0.57 & 0.07 & 0.05 \\
\hline Ag-4 & 43.14 & 0.12 & 52.11 & 3.05 & 1.10 & 0.34 & 0.06 & 0.04 \\
\hline
\end{tabular}

${ }^{\text {a }}$ Percentages related to original dry aggregate.

${ }^{b}$ The methods specified by the European Standard EN-196 were followed for the chemical analyses.

${ }^{\mathrm{c}} \mathrm{R}_{2} \mathrm{O}_{3}$ expresses the percentage of $\mathrm{Fe}, \mathrm{Al}$ and $\mathrm{Ti}$ as oxides. 
Table 4. Results of X-ray diffraction in aggregates.

\begin{tabular}{ccc}
\hline Aggregate & $\begin{array}{c}\text { Calcite } \\
\left(\mathbf{C a C O}_{3}\right) \\
\text { ICDD 05-0586 }\end{array}$ & $\begin{array}{c}\alpha-\text { Quartz } \\
\left.\mathbf{( S i O}_{\mathbf{2}}\right) \\
\text { ICDD 85-798 }\end{array}$ \\
\hline Ag-1 & $* \mathrm{c}$ & $* * \mathrm{~b}$ \\
Ag-2 & $*$ & $* *$ \\
Ag-3 & $* * *$ a & $\mathrm{T}^{\mathrm{d}}$ \\
Ag-4 & $* * *$ & $\mathrm{~T}$ \\
\hline${ }^{\mathrm{a}}>90 \%$ & & \\
${ }^{\mathrm{b}}{ }_{50-90 \%}$ & & \\
${ }^{\mathrm{c}} 10-50 \%$ & & \\
${ }^{\mathrm{d}}$ Traces $(<5 \%)$ & &
\end{tabular}


Table 5. Equivalences volume proportion/weight proportion

\begin{tabular}{ccccc}
\hline $\begin{array}{c}\text { Volume } \\
\text { Proportion }\end{array}$ & Material & $\begin{array}{c}\text { Volume } \\
(\mathbf{L})\end{array}$ & $\begin{array}{c}\text { Weight } \\
\text { (g) }\end{array}$ & $\begin{array}{c}\text { Weight } \\
\text { Proportion }\end{array}$ \\
\hline \multirow{2}{*}{$1: 1$} & Lime & 2.00 & 800 & $1: 3.75$ \\
& Aggregate & 2.00 & 3000 & $1: 7.5$ \\
\multirow{2}{*}{$1: 2$} & Lime & 1.33 & 533.33 & $1: 11.25$ \\
& Aggregate & 2.67 & 4000 & $1: 15$ \\
\multirow{2}{*}{$1: 3$} & Lime & 1.00 & 400 & \\
& Aggregate & 3.00 & 4500 & $1: 18.75$ \\
\hline \multirow{5}{*}{$1: 4$} & Lime & 0.80 & 320 & \\
& Aggregate & 3.20 & 4800 & \\
\hline
\end{tabular}


Table 6. Results of thermogravimetric analysis in lime B mortars with Ag-4.

\begin{tabular}{|c|c|c|c|c|c|c|c|}
\hline B/Ag & $\begin{array}{l}\text { Test } \\
\text { day }\end{array}$ & $\begin{array}{c}\text { Portlandite (\%) } \\
\left(\mathrm{Ca}(\mathrm{OH})_{2}\right)\end{array}$ & $\begin{array}{c}\text { Calcite (\%) } \\
\left(\mathrm{CaCO}_{3}\right) \\
\end{array}$ & B/Ag & $\begin{array}{l}\text { Test } \\
\text { day }\end{array}$ & $\begin{array}{c}\text { Portlandite (\%) } \\
\left(\mathrm{Ca}(\mathrm{OH})_{2}\right)\end{array}$ & $\begin{array}{c}\text { Calcite (\%) } \\
\left(\mathrm{CaCO}_{3}\right)\end{array}$ \\
\hline \multirow{6}{*}{$\ddot{-}$} & 3 & 17.27 & 80.23 & \multirow{6}{*}{$\stackrel{+}{-}$} & 3 & 3.51 & 94.54 \\
\hline & 7 & 14.22 & 83.19 & & 7 & 3.88 & 94.49 \\
\hline & 28 & 14.12 & 83.65 & & 28 & 2.93 & 95.31 \\
\hline & 91 & 11.55 & 86.36 & & 91 & 1.67 & 96.61 \\
\hline & 182 & 16.97 & 81.31 & & 182 & 1.56 & 97.17 \\
\hline & 365 & 4.18 & 93.90 & & 365 & 0.99 & 97.84 \\
\hline \multirow{6}{*}{$\stackrel{\sim}{-}$} & 3 & 9.00 & 89.28 & \multirow{6}{*}{$\stackrel{n}{-}$} & 3 & 2.33 & 95.76 \\
\hline & 7 & 7.81 & 90.35 & & 7 & 2.68 & 95.92 \\
\hline & 28 & 6.77 & 90.84 & & 28 & 2.12 & 96.35 \\
\hline & 91 & 3.42 & 94.78 & & 91 & 0.45 & 98.21 \\
\hline & 182 & 7.96 & 90.54 & & 182 & 0.82 & 97.76 \\
\hline & 365 & 1.46 & 96.86 & & 365 & 0.43 & 98.28 \\
\hline \multirow{6}{*}{$\stackrel{?}{-}$} & 3 & 5.36 & 93.03 & & & & \\
\hline & 7 & 5.42 & 92.90 & & & & \\
\hline & 28 & 4.31 & 94.13 & & & & \\
\hline & 91 & 3.07 & 95.35 & & & & \\
\hline & 182 & 2.14 & 96.25 & & & & \\
\hline & 365 & 1.30 & 97.52 & & & & \\
\hline
\end{tabular}


Table 7. Open porosity (\%) in mortars tested after 365 days.

\begin{tabular}{|c|c|c|c|c|c|}
\hline & B/Ag & Ag-1 & Ag-2 & Ag-3 & Ag-4 \\
\hline \multirow{5}{*}{ 岁 } & 1:1 & 24.11 & 27.09 & 26.05 & 27.27 \\
\hline & 1:2 & 20.51 & 24.24 & 22.91 & 24.25 \\
\hline & 1:3 & 19.08 & 21.72 & 20.94 & 21.03 \\
\hline & 1:4 & 17.90 & 19.88 & 20.26 & 19.30 \\
\hline & 1:5 & 16.51 & 19.68 & 18.79 & 19.35 \\
\hline \multirow{5}{*}{ 苛 } & 1:1 & 28.42 & 30.63 & 29.70 & 30.45 \\
\hline & 1:2 & 23.89 & 25.41 & 25.51 & 26.51 \\
\hline & 1:3 & 22.23 & 23.25 & 24.50 & 24.61 \\
\hline & 1:4 & 18.40 & 20.30 & 21.28 & 22.72 \\
\hline & 1:5 & 19.79 & 21.06 & 20.80 & 21.35 \\
\hline
\end{tabular}




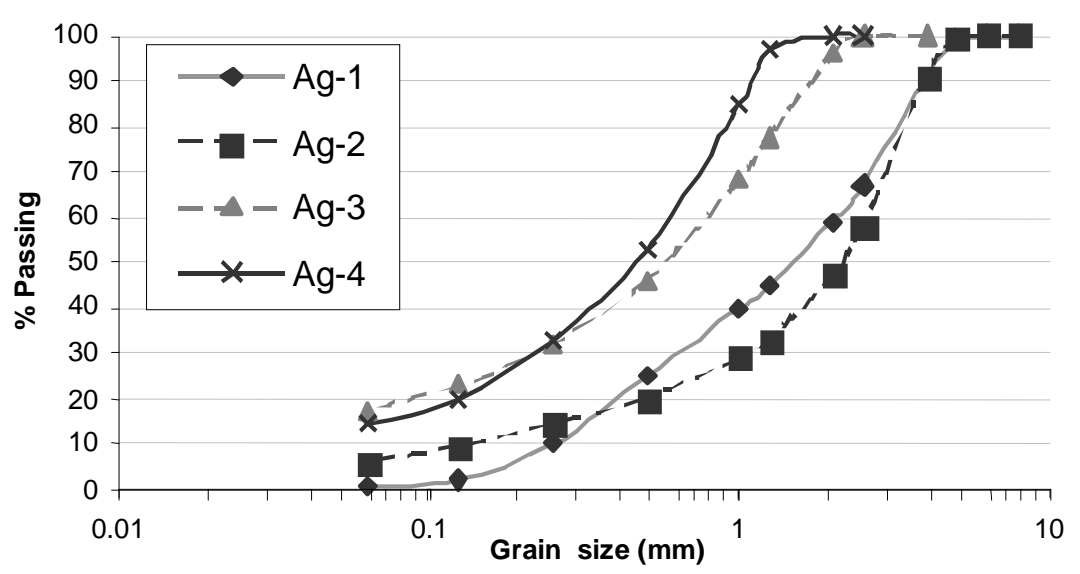

Figure 1. Grain size distributions of the aggregates. 


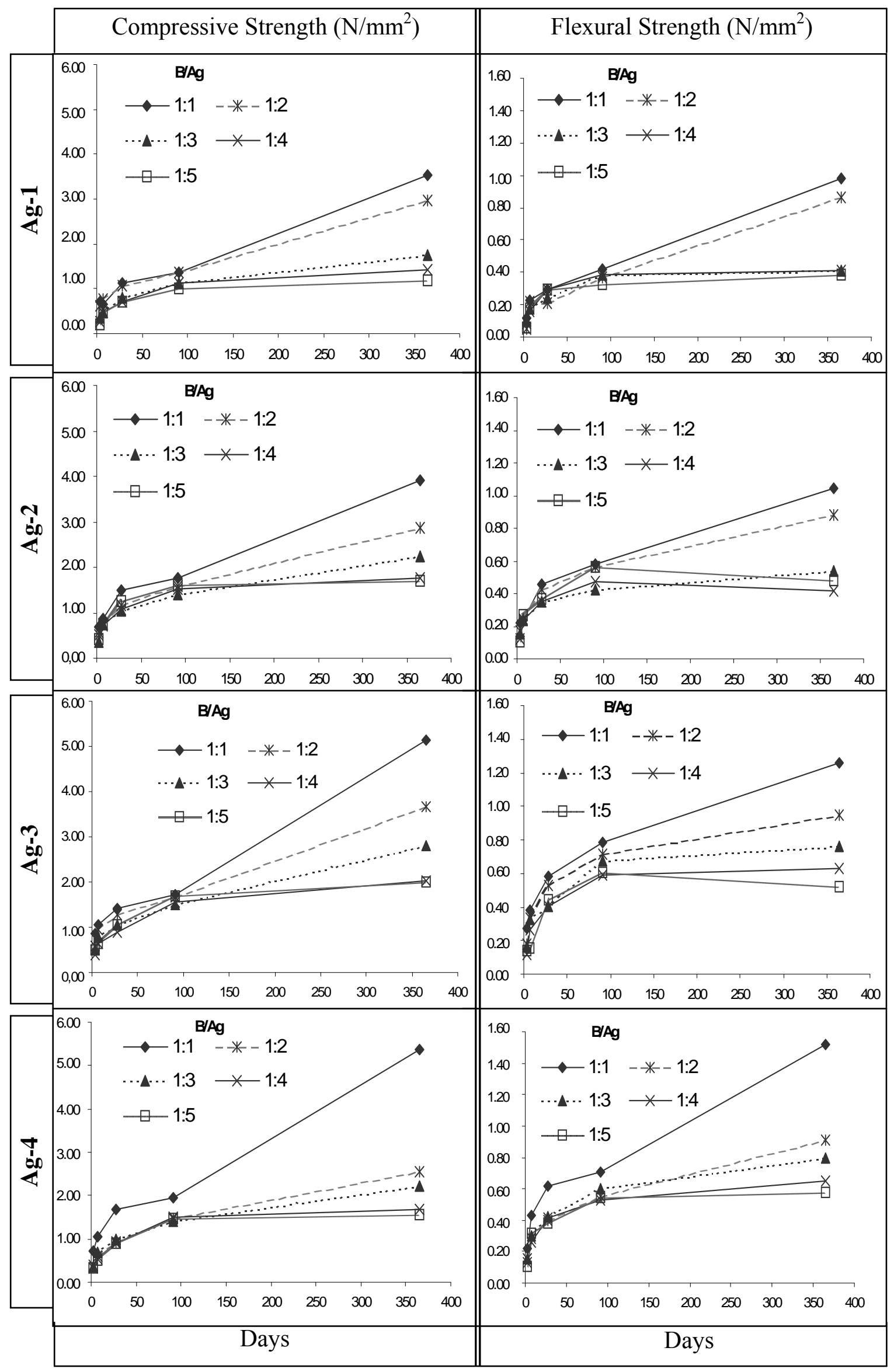

Figure 2. Strength results in lime A mortars with different aggregates. 


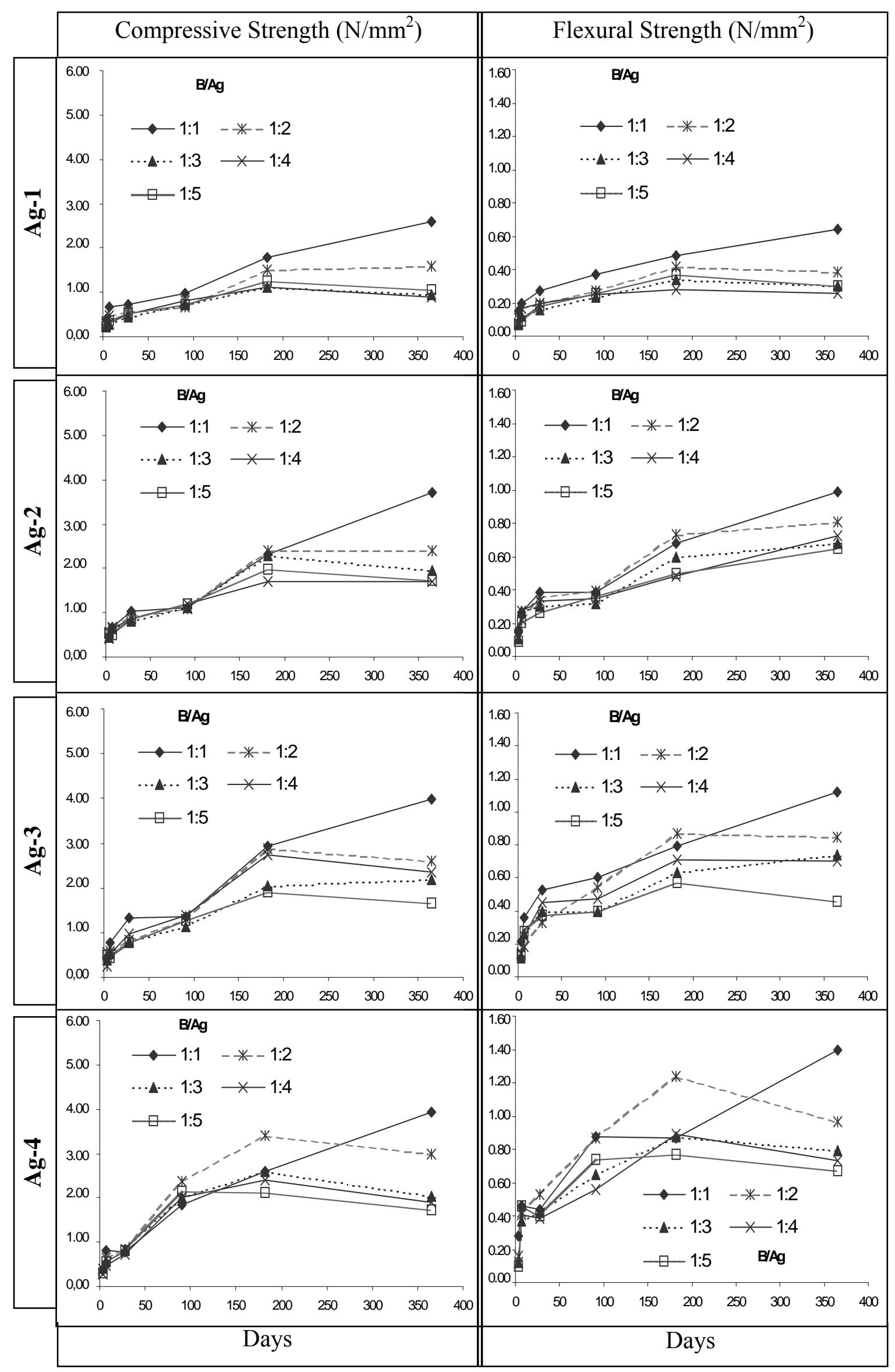

Figure 3. Strength results in lime B mortars with different aggregates. 


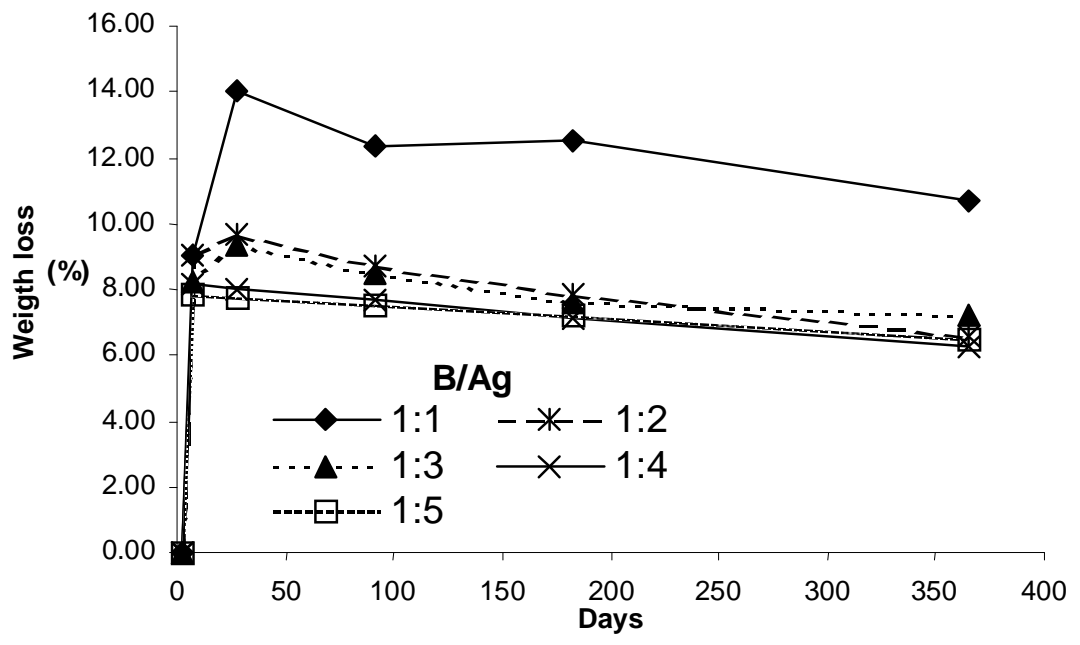

Figure 4. Weight loss vs curing time in lime B mortars with Ag-4. 


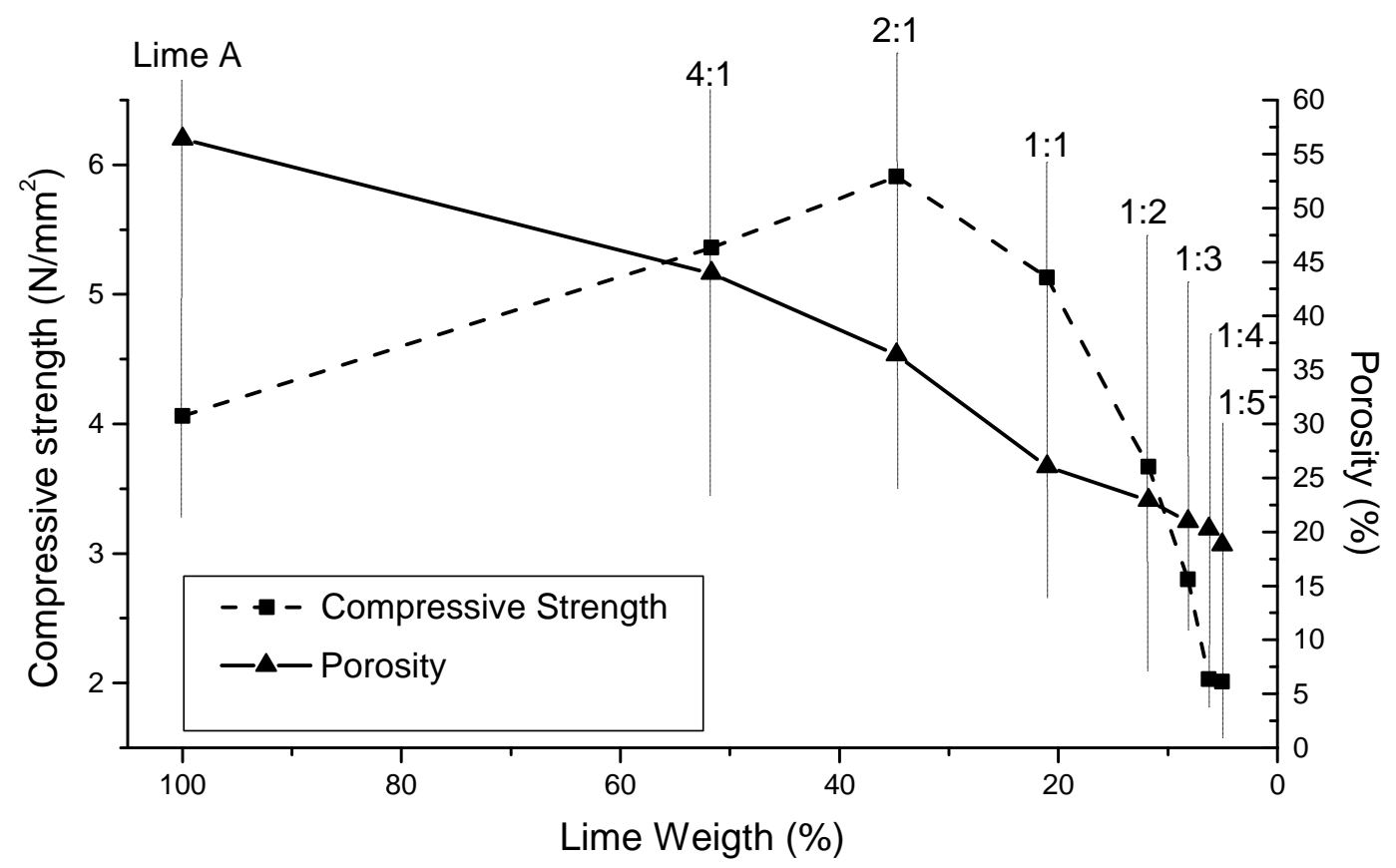

Figure 5. Porosity and compressive strength vs percentage of lime in lime A mortars with Ag-3 tested after 365 days. Binder:aggregate ratios (B/Ag) are expressed on top of points. 


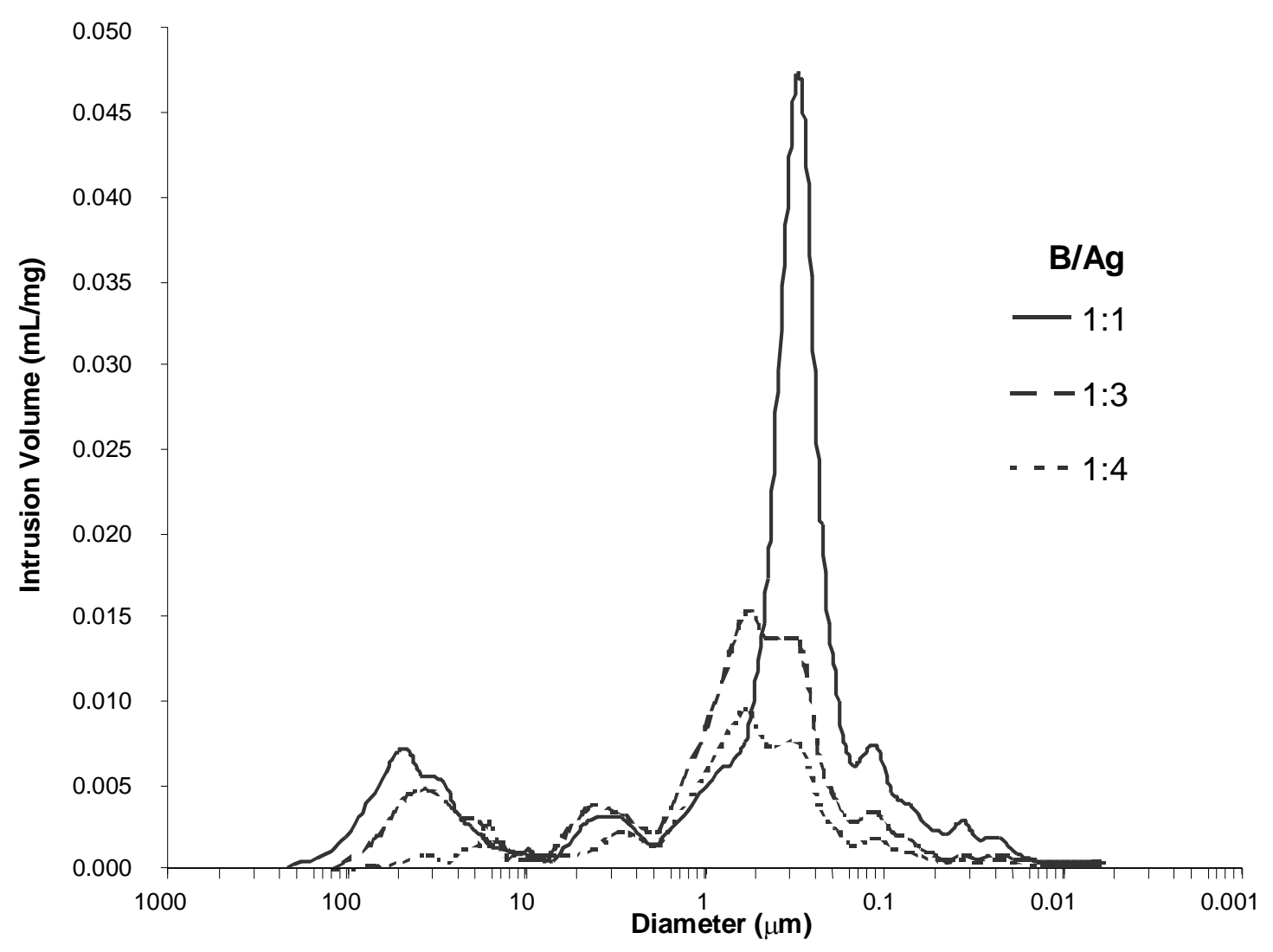

Figure 6. Pore size distribution (pore diameter) in lime B with Ag-2 mortars tested after 365 days. 


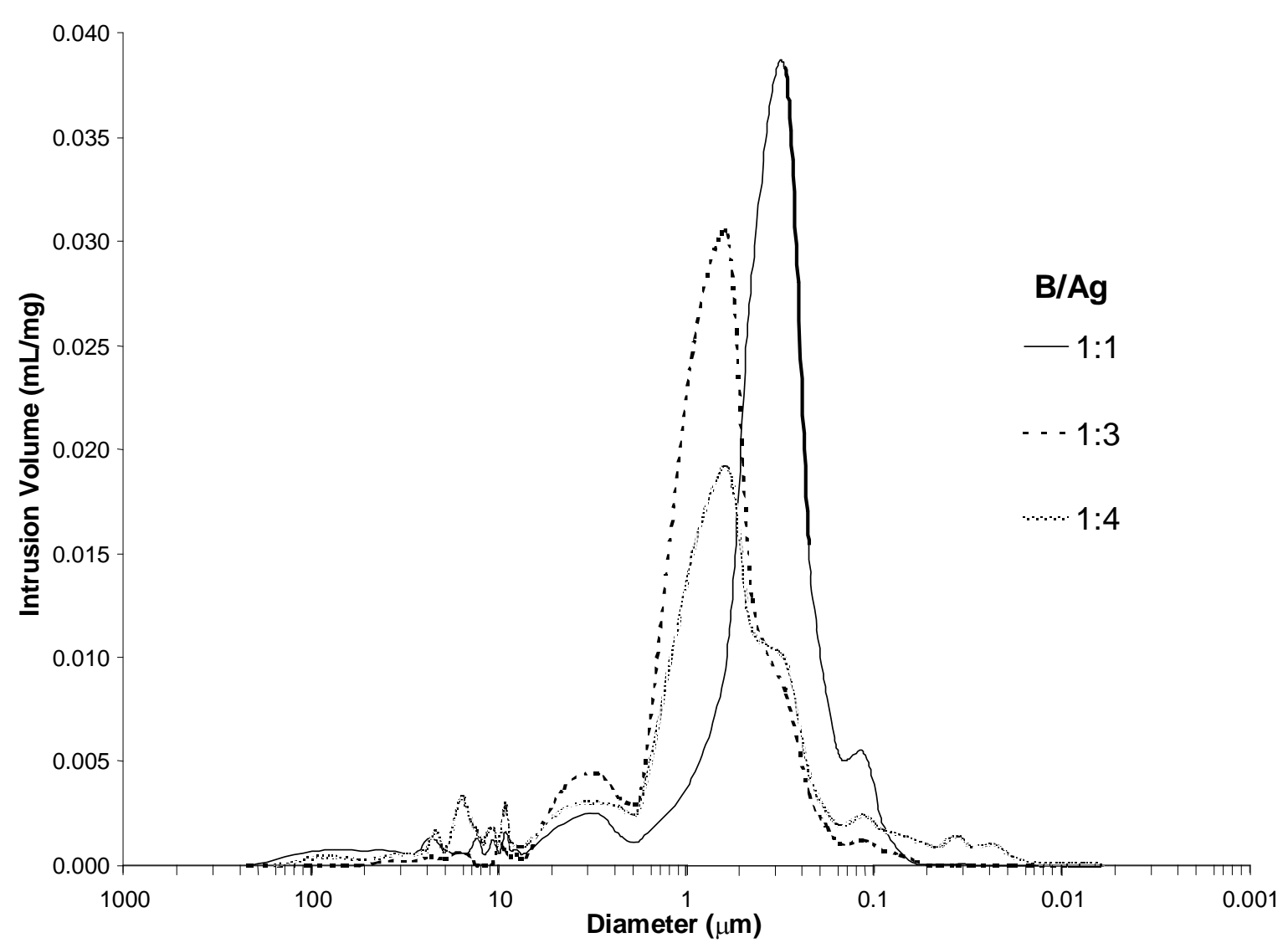

Figure 7. Pore size distribution (pore diameter) in lime B with Ag-3 mortars tested after 365 days. 